\title{
A Comparative Study of Electrical Characterization of $P$-Doped Distributed Bragg Reflectors Mirrors for 1300 nm Vertical Cavity Semiconductor Optical Amplifiers
}

\author{
Faten A. Chaqmaqchee \\ Department of Physics, Faculty of Science and Health, Koya University, Koya KOY45, Kurdistan Region - F.R. Iraq
}

\begin{abstract}
This paper presents an electrical analysis of various diameters of two $p$-types of $\mathrm{GaAs} / \mathrm{Al}_{0.9} \mathrm{Ga}_{0.1} \mathrm{As}$ and two $p$-types of $\mathrm{GaAs} / \mathrm{Al}_{0.3} \mathrm{Ga}_{0.7} \mathrm{As} / \mathrm{Al}_{0.9} \mathrm{Ga}_{0.1} \mathrm{As}$ distributed Bragg reflectors (DBRs) mirrors structure grown on undoped and on $p$-doped GaAs, which affects the characteristics of $1300 \mathrm{~nm}$ vertical cavity surface emitting lasers (VCSELs) and vertical cavity semiconductor optical amplifiers (VCSOAs). Electrical characterizations and Hall measurements of current-voltage $(I V)$ for $\mathbf{G a A s} / \mathbf{A l}_{0.9} \mathbf{G a}_{0.1}$ As linear DBRs and $\mathrm{GaAs} / \mathrm{Al}_{0.3} \mathbf{G a}_{0.7} \mathrm{As}_{\mathbf{A}} \mathrm{Al}_{0.9} \mathbf{G a}_{0.1}$ As graded DBRs were also performed at temperatures between 13 and $300 \mathrm{~K}$. Consequently, p-type DBRs are designed with graded composition interfaces technique. The smaller mesa diameters are used to reduce vertical and longitudinal resistances and to limit the heating effect and improve the characteristics of VCSEL/VCSOA devices.
\end{abstract}

Index Terms-AlGaAs/GaAs, Current-voltage, Distributed Bragg reflectors, Mobility.

\section{INTRODUCTION}

A distributed Bragg reflector (DBRs) are called Bragg mirror or quarter wavelength stacks of alternating materials with varied refractive index (Garmire, 2003; Marciniak, et al., 2020; Chaqmaqchee and Lott, 2020). DBRs represent an essential layer of an optical cavity of vertical-cavity surface-emitting lasers (VCSELs) (Croquette and Hou, 1997; Chaqmaqchee, 2019) and vertical cavity semiconductor optical amplifiers (VCSOAs) (Wang et al., 2019; Chaqmaqchee, Abubekr Salh, and Sabri, 2020) for a target wavelength of $1300 \mathrm{~nm}$. The optically active layers of such optoelectronic devices can be grown between two DBR mirrors. Epitaxial growth of III-V semiconductor compounds of $\mathrm{AlGaAs} / \mathrm{GaAs}$ DBRs was demonstrated in 1983 by molecular-beam epitaxy (MBE)

ARO-The Scientific Journal of Koya University

Vol. IX, No.1 (2021), Article ID: ARO.10741, 06 pages

DOI: 10.14500/aro.10741

Received 24 October 2020; Accepted: 29 April 2021

Regular research paper: Published: 03 June 2021

Corresponding author's e-mail: Email: faten.chaqmaqchee@,

koyauniversity.org

Copyright (C) 2021 Faten A. Chaqmaqchee. This is an open-access

article distributed under the Creative Commons Attribution License.
(Ogura et al., 1983), which is in use today. The alloy AlGaAs/ GaAs is of great interest for many high speed electronics and optoelectronic applications because the lattice parameter difference between these two compounds is very small. The serious problem with VCSELs and VCSOAs is abnormally high resistance in the upper of quarter wavelength stacks (Zhang, ElAfandy and Han, 2019; Chaqmaqchee, et al. 2012). The DBRs are requiring low resistance to allow current injection and reduce the carrier heating in quantum wells (QWs). When the level doping of the DBR is high, it causes a reduction in Fermi level and thus a decrease in potential barrier height (Pickrella et al., 2005) as well efficient in increasing the tunneling current. However, it is also related to higher internal optical losses due to the free carrier absorption. Therefore, $p$-type DBRs are regularly designed using graded composition interfaces and eventually, high doping concentration to reduce the series resistance (Pohl, et al. 2018).

In this paper, a comprehensive study of two $p$-types of GaAs/ $/ \mathrm{Al}_{0.9} \mathrm{Ga}_{0.1} \mathrm{As}$ plus two $p$-types of $\mathrm{GaAs} / \mathrm{Al}_{0.3} \mathrm{Ga}_{0.7} \mathrm{As} /$ $\mathrm{Al}_{0.9} \mathrm{Ga}_{0.1} \mathrm{As}$ on undoped and $p$-doped GaAs substrates using different diameters is presented. Current-voltage characteristics of $p$-type DBRs at temperatures between $13 \mathrm{~K}$ and $300 \mathrm{~K}$ are experimentally demonstrated. This includes comparison between various mesa diameters structure and Hall measurements. High performance DBRs are confirmed with graded layers, which simultaneously reduce electrical resistivity, enabling current to inject directly into QWs of VCSEL and VCSOA devices.

\section{MATERIAL AND MethodS}

DBR samples (two with linear and two with graded interface) were grown by MBE in the National Epitaxy Facility at the University of Sheffield, United Kingdom. The growth rate for $\mathrm{AlGaAs} / \mathrm{GaAs}$ components (DBR on an undoped GaAs and on a doped p-type GaAs substrate) is about $1.0 \mathrm{ml} / \mathrm{s}(0.28 \mathrm{~nm} / \mathrm{s})$. During the sample growth, the beryllium cell's temperature is kept constant at $620^{\circ} \mathrm{C}$. The growth rate is about $1.0 \mathrm{ml} / \mathrm{s}$ for the $\mathrm{Al}_{0.3} \mathrm{Ga}_{0.7} \mathrm{As}$ but it sets on $0.33 \mathrm{ml} / \mathrm{s}(0.94 \mathrm{~nm} / \mathrm{s})$ for the $\mathrm{Al}_{0.9} \mathrm{Ga}_{0.1}$ As part because they cannot grow it with independent sources. The temperature 
is kept between 600 and $610^{\circ} \mathrm{C}$ throughout the growth process. The growth rate for the graded samples might be slightly variable, but all the time it is kept at around $1.0 \mathrm{ml} / \mathrm{s}$. With these conditions, the nominal doping concentration is not constant across the DBRs but changes according to Fig. 1. Therefore, in conclusion the graded DBRs use two gallium cells and one aluminum cell. To have two different $\mathrm{Al}$ compositions, the Ga cell has been changed and uses the same $\mathrm{Al}$ flux: The growth rates for the three DBR layers are $1.1 \mathrm{ml} / \mathrm{sec}$ for the GaAs (Ga1+Ga2 cells), $1.5 \mathrm{ml} / \mathrm{sec}$ for the

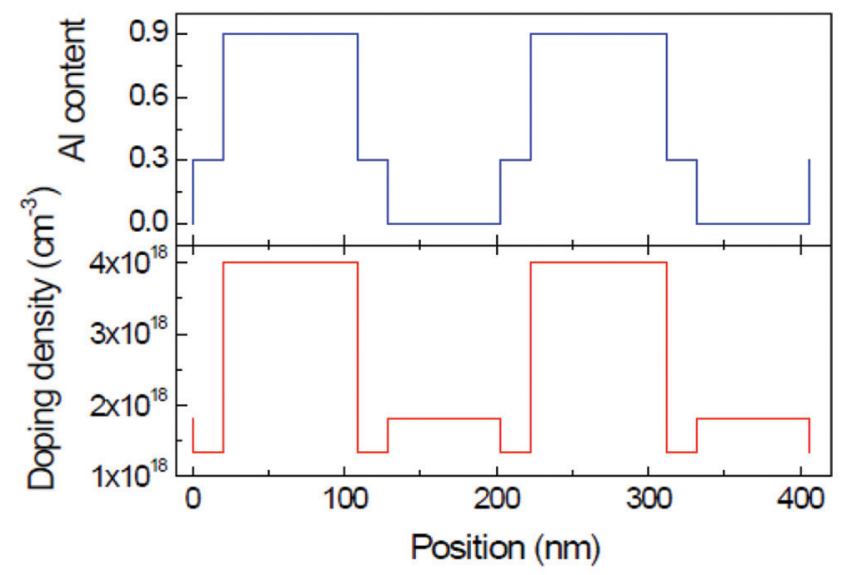

Fig. 1. Nominal doping profile changes across the semiconductor mirror distributed Bragg reflector period with two $\mathrm{Al}$ compositions of $90 \%$ and $30 \%$.
$\mathrm{Al}(30 \%)$, GaAs ( $\mathrm{Al}+\mathrm{Ga} 2$ cells), and only $0.5 \mathrm{ml} / \mathrm{s}$ for the $\mathrm{Al}$ $(90 \%), \mathrm{GaAs}(\mathrm{Al}+\mathrm{Ga} 1$ cells) to give some very good results in terms of resistivity.

Two DBRs samples were fabricated into mesa-rings to investigate the vertical transport properties of the DBRs. The other two samples are fabricated into Hall bar shaped samples to study longitudinal transport along the layers. In the linear case, the DBR samples consist of 14 periods of GaAs/ $/ \mathrm{Al}_{0.9} \mathrm{Ga}_{0.1} \mathrm{As}$ and are grown on undoped and $p$-doped GaAs substrates. In graded samples, 14 periods of GaAs/ $\mathrm{Al}_{0.3} \mathrm{Ga}_{0.7} \mathrm{As} / \mathrm{Al}_{0.9} \mathrm{Ga}_{0.1} \mathrm{As}$, have been grown on an undoped and a $p$-doped substrate. The thickness and composition of the DBR layers have been designed to be suitable for VCSELs and VCSOAs operating at $1300 \mathrm{~nm}$. To analyses the reflectance of the layers at an interface, the transmission matrix approach is used (Macleod, 1986), which includes the individual properties of the various layers.

The surface roughness for the two samples of AlGaAs/ GaAs DBR on undoped GaAs substrate (coded VN1734) and AlGaAs/GaAs DBR on $p$-type doped GaAs substrate (coded VN1743) has been checked by atomic force microscope. In Fig. 2a, the surface root mean square (RMS) roughness is very low $\sim 0.2 \mathrm{~nm}$ and roughly the same for all the structure, independently of the substrate type as in Fig. 2b. In Fig. 2c and $\mathrm{d}$, the stopband center wavelength variation across the wafer of graded DBRs (coded VN1800 and VN1802) is $<3.5 \mathrm{~nm}$, which shows good flux homogeneity in the system. The stopband center wavelength is longer than the targeted value but the samples are ideal for current-voltage characterization.
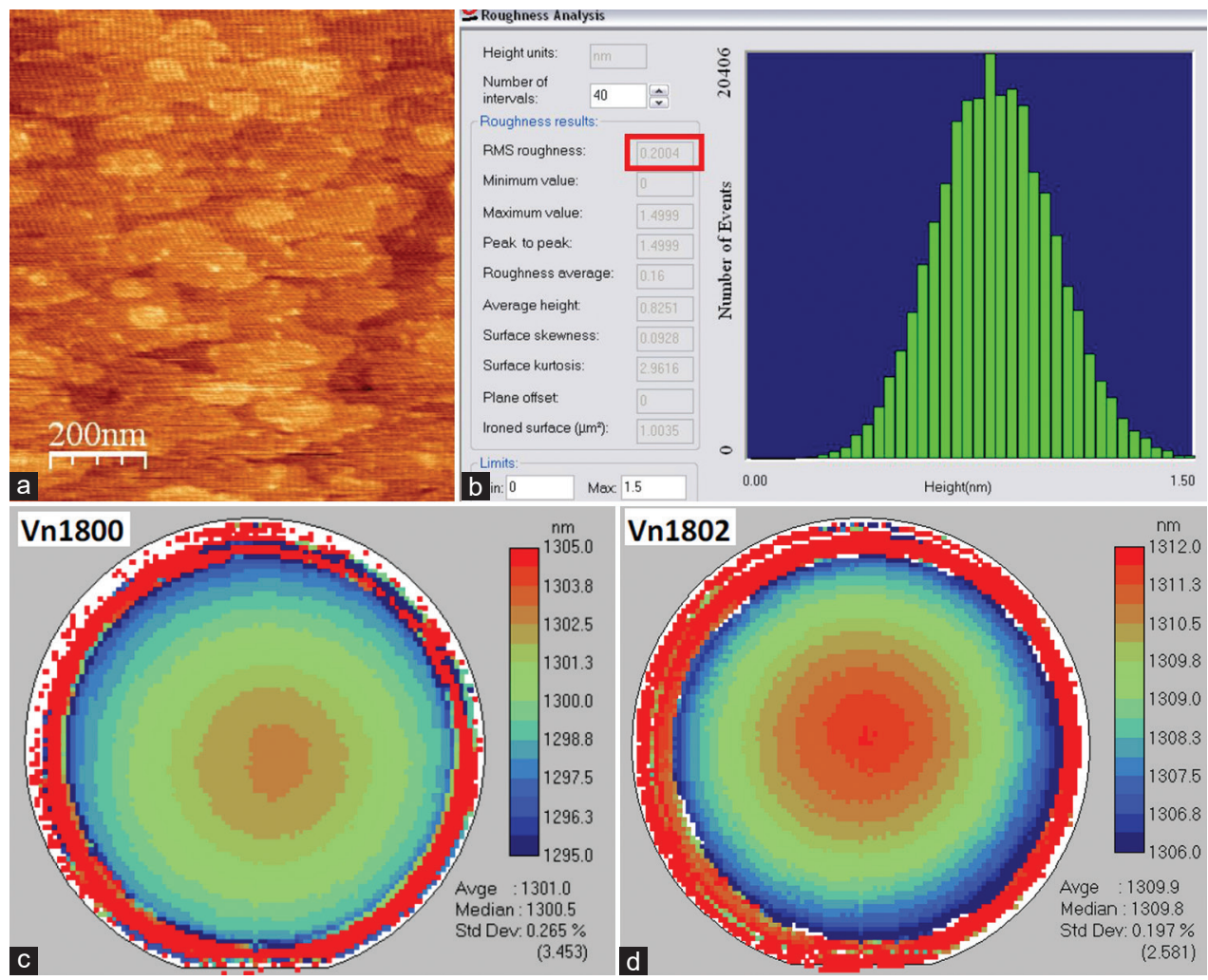

Fig. 2. (a) Atomic force micrographs for surface characterization of the distributed Bragg reflector (DBR) on $p$-type GaAs substrate, where (b) the root mean square roughness at around $0.2 \mathrm{~nm}$, and ( $\mathrm{c}$ and d) variation across the wafer- stopband center wavelength for graded DBRs grown on an undoped (VN1800) and a $p$-doped (VN1802) substrate. 

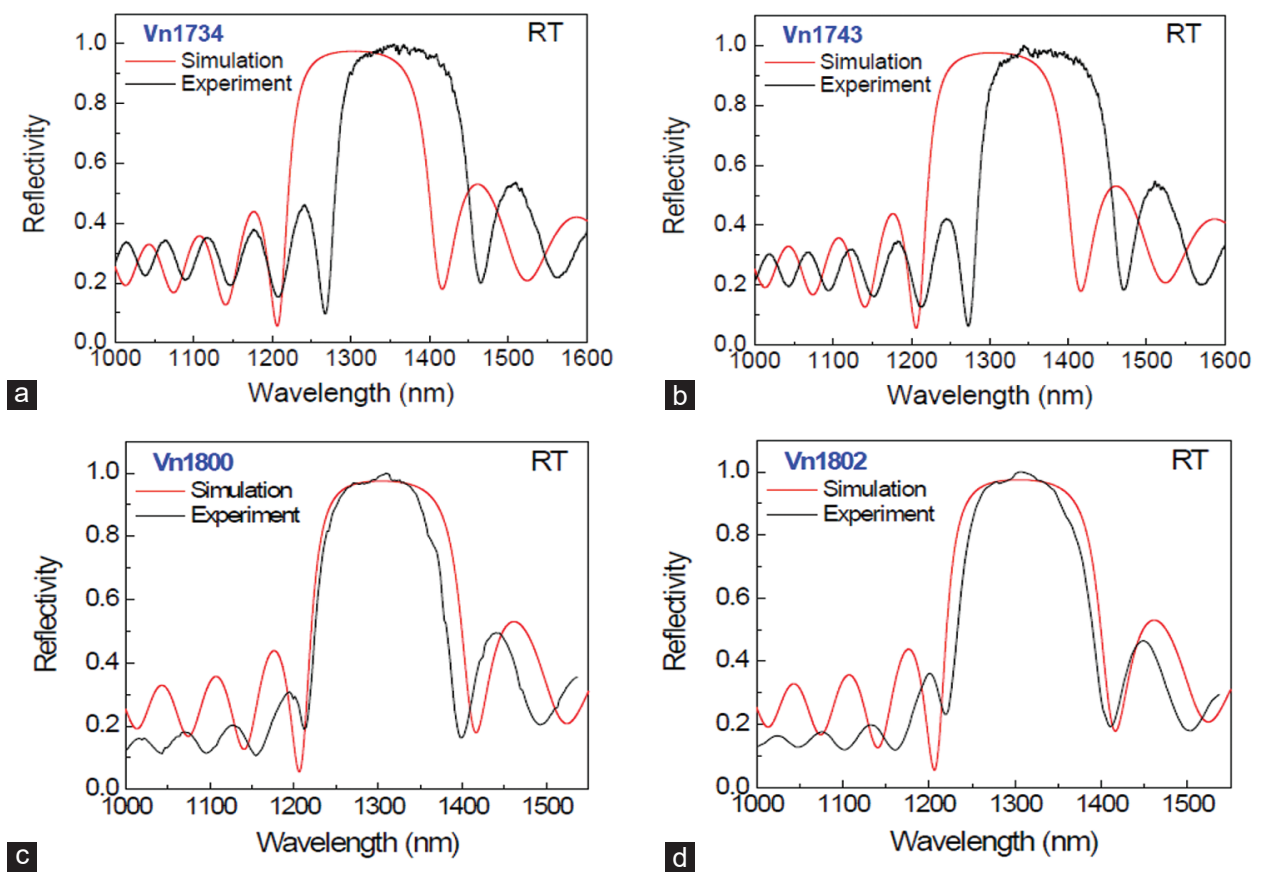

Fig. 3: Room temperature reflectivity's of 14 Bragg pairs confirming the agreement between measurements and simulations of AlGaAs/GaAs distributed Bragg reflector on (a) undoped GaAs substrate (coded VN1734), (b) p-type GaAs substrate (coded VN1743), (c) undoped GaAs substrate (coded VN1800), and (d) $p$-type GaAs substrate (coded VN1802).
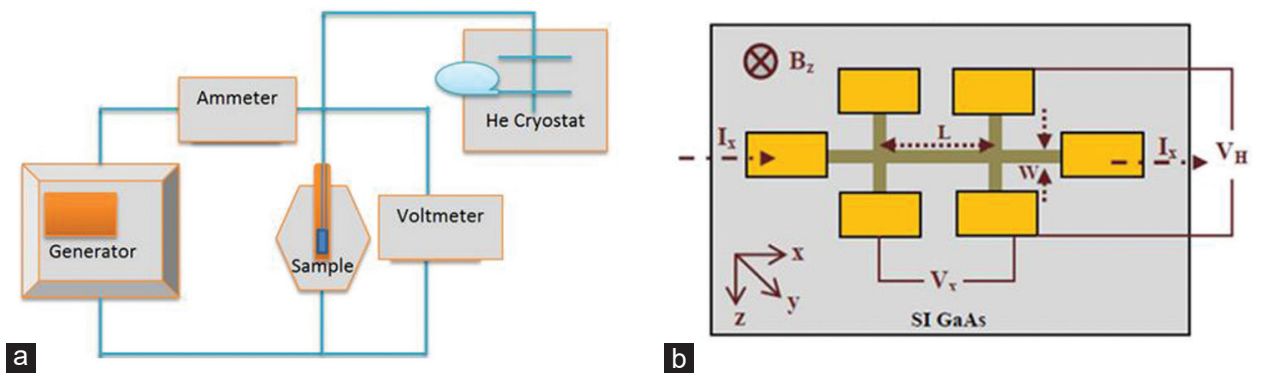

Fig. 4. Schematic diagram illustrates (a) the operation of the oxford closed cycle cooler system for current-voltage (IV) measurements, and (b) the Hall Effect on a semiconductor sample.
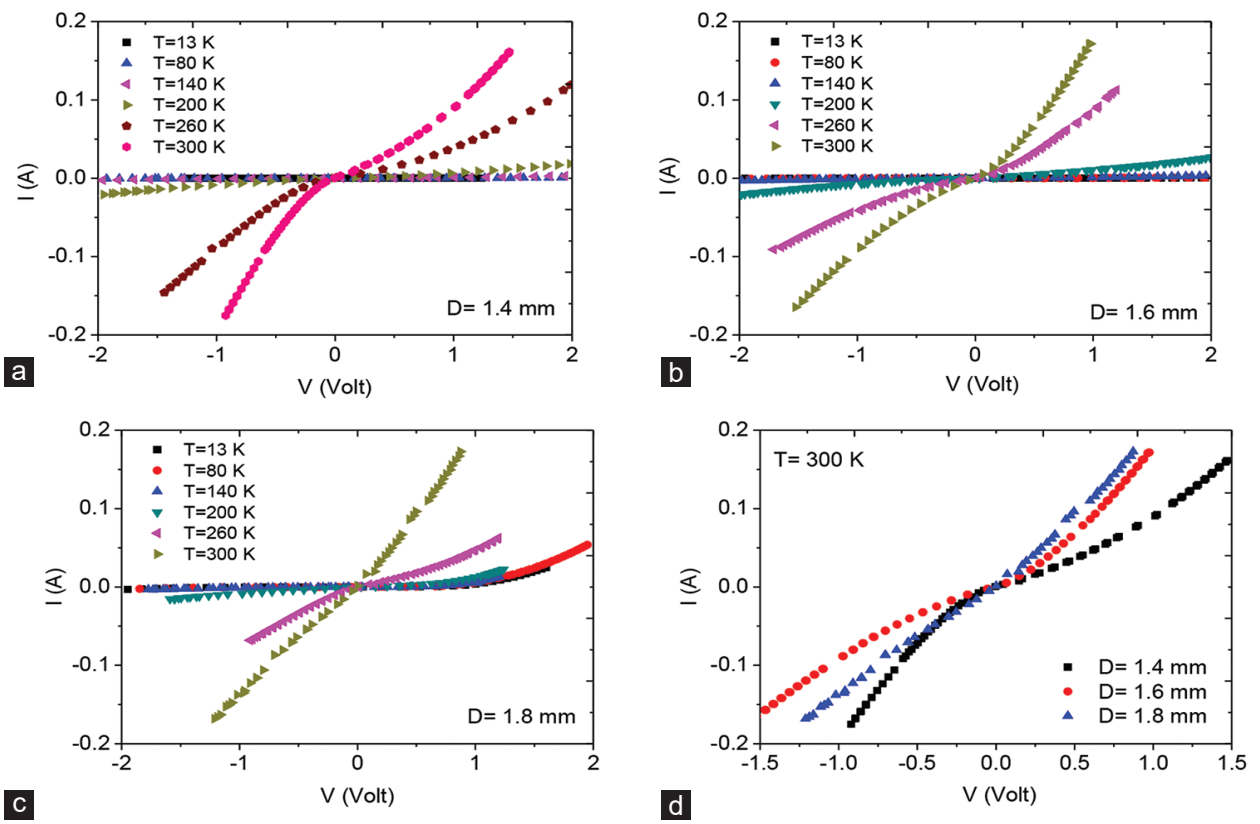

Fig. 5. Electrical characterizations (IV) for linear samples of distributed Bragg reflector (DBRs) with diameters of (a) $1.4 \mathrm{~mm}$, (b) $1.6 \mathrm{~mm}$, and (c) $1.8 \mathrm{~mm}$ at $\mathrm{T}=13$ to $300 \mathrm{~K}$, (d) $I V$ for diameters of $1.4,1.6$, and $1.8 \mathrm{~mm}$ DBRs at $300 \mathrm{~K}$. 

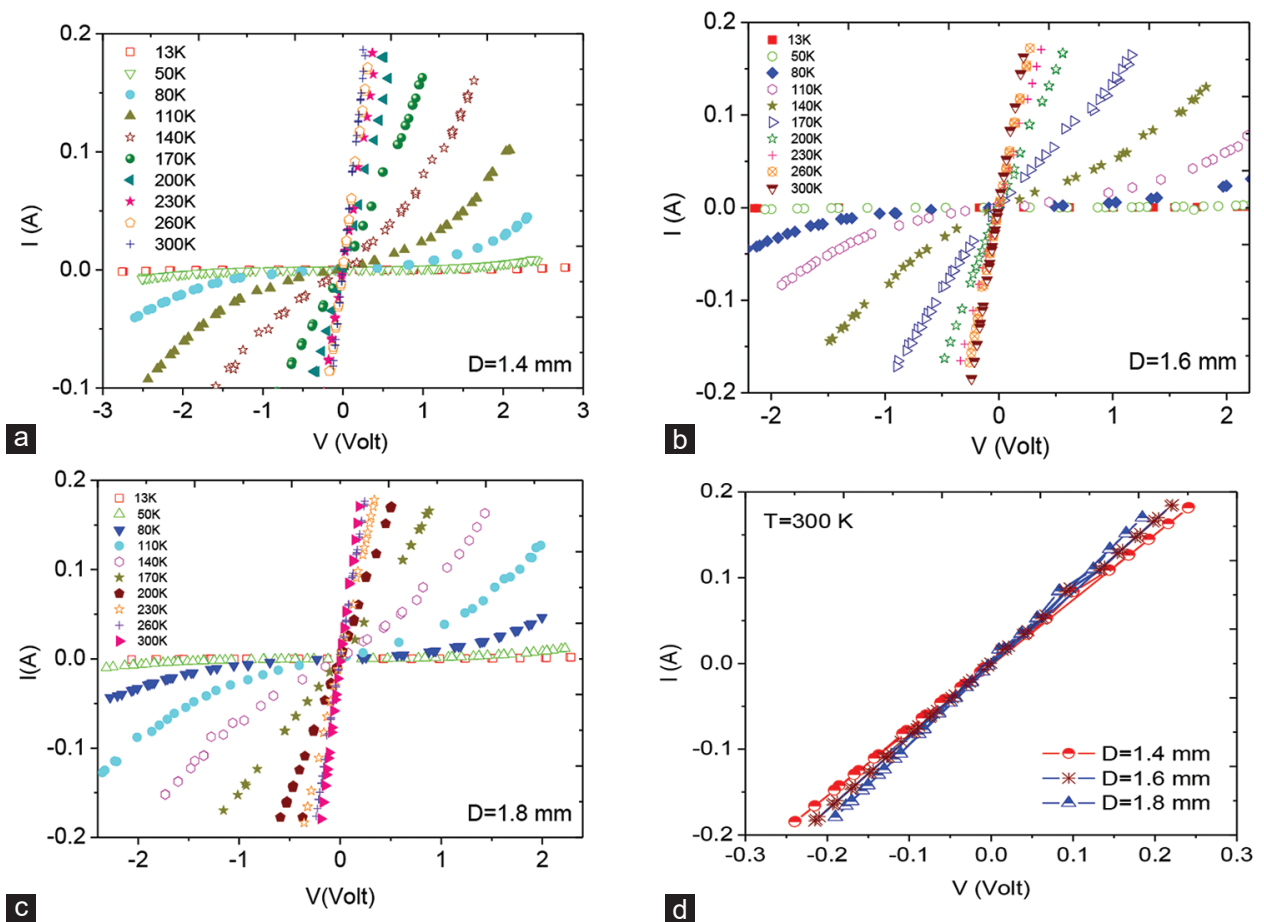

Fig. 6. Electrical characterizations (IV) for the graded samples of distributed Bragg reflector (DBRs) coded (VN1802) with diameters of (a) 1.4 mm, (b) $1.6 \mathrm{~mm}$ and (c) $1.8 \mathrm{~mm}$ at $\mathrm{T}=13$ to $300 \mathrm{~K}$, and (d) for various DBRs diameters at $300 \mathrm{~K}$.

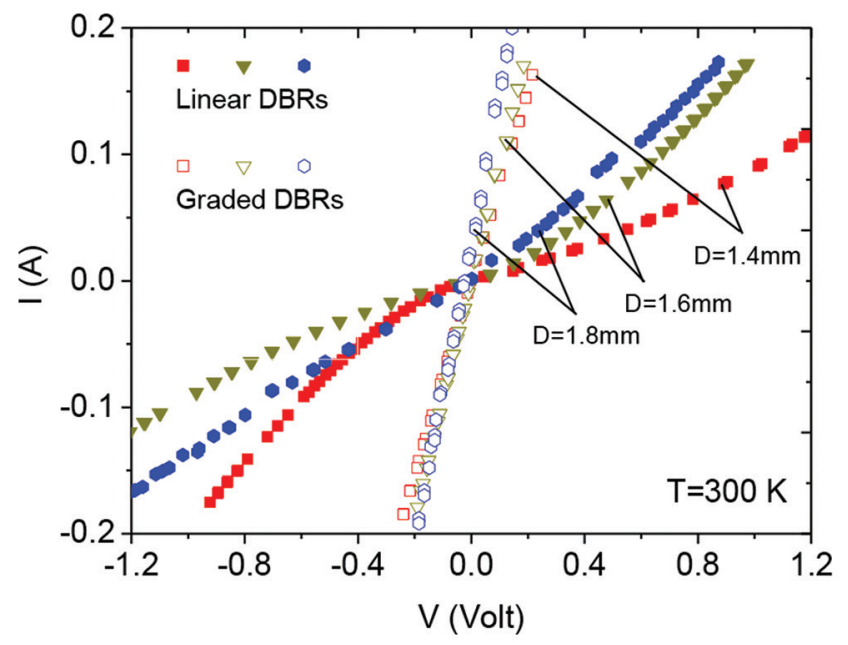

Fig. 7. Comparative current versus voltage measurements between linear distributed Bragg reflectors (DBRs) coded (VN1734) and graded DBRs coded (VN 1802) samples.

In Fig. 3a and b, room temperature reflectivity spectra for both samples coded VN1734 and VN1743 are nearly the same with only a $6 \mathrm{~nm}$ shift (thickness difference lower than $0.5 \%$ ) between the two samples. In Fig. $3 c$ and $d$, the reflectivity spectra for samples coded VN1800 and VN1802 are in agreement with the simulation results.

\section{EXPERIMENTAL DETAILS}

Electrical resistivity and Hall Effect measurements are the most commonly used techniques for semiconductor characterization. Several electrical characterizations of DBR mirrors have been achieved including longitudinal and vertical carrier transport and hence device applications. The current-voltage (IV) characteristics are recorded at various temperatures from 13 to $300 \mathrm{~K}$. As shown in Fig. 4a, a 40 $\mathrm{MHz}$ Arbitrary waveform (TGA1421) generator is used to supply a positive ramp waveform of about $10 \mathrm{~s}$ duration with amplitude up to $20 \mathrm{~V}_{\mathrm{pp}}$ (peak to peak). This experiment was performed with a closed-cycle Helium cryostat system, and the temperature controller in the Cryodrive compressor unit. The cold head is connected to the base of the sample by a copper link which is fitted with a temperature sensor and a heater to allow variable temperature operation. During the running of the system, if the sample rod is removed from the fitted holder, a slight over pressure of Helium exchange gas should be preserved. The outer vacuum should be evacuated to a pressure of $<10-5$ mbar using a suitable rotary/turbomolecular pumping system. Once the sample rod is inserted in place, the sample space should be evacuated to $\sim 10-1$ mbar using a rotary pump. Once the cryostat temperature has reached $220 \mathrm{~K}$, Helium exchange gas must be added to the sample space. The Helium gas is added using a football bladder which is already connected to the sample space valve. Then with the heater in MAN mode, it can set to the low temperature at around $10 \mathrm{~K}$.

In addition, electrical characterizations of DBR mirrors have been achieved using longitudinal carrier transport. The Hall bar shaped sample is effectively recommended for quantitative measurements over a wide range of temperatures and can be tested to provide information about material impurities, uniformity and mobility limiting scattering mechanisms. The simple Hall bar has side arms, in which the current flows from left to right under an applied electric 

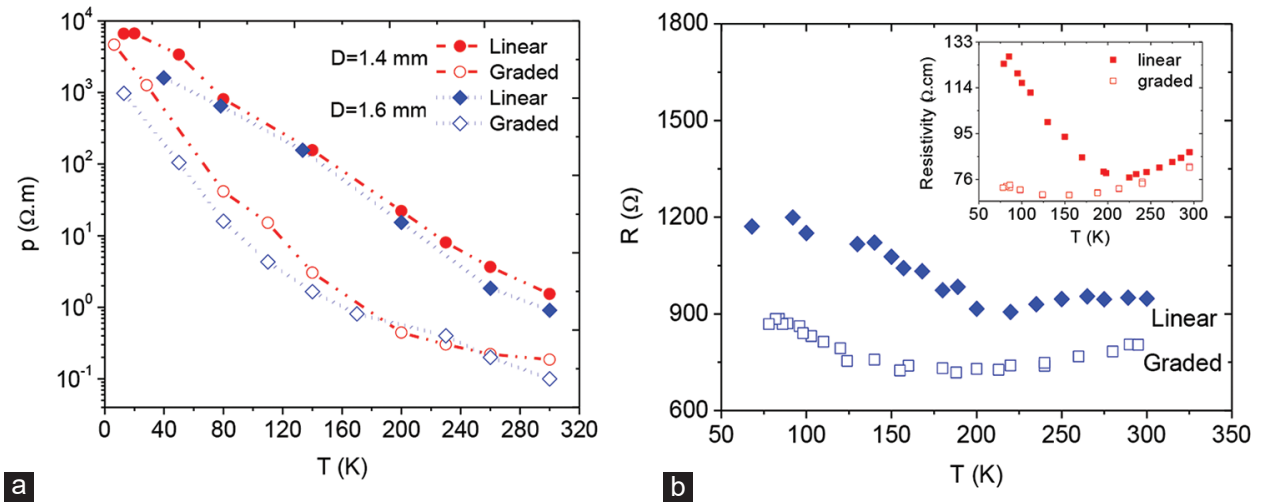

Fig. 8. Temperature dependence of the (a) vertical resistivity in logarithmic scale with linear and graded DBRs diameters of 1.4 and 1.6 mm, (b) Hall resistance under the current flow of $480 \mu \mathrm{A}$. The inset shows the resistivity against temperature.

field $E_{y}$ as depicted in Fig. 4b. The magnetic induction $B_{z}$ is applied normal to the sample surface and to the direction of current flow $\mathrm{I}_{\mathrm{x}}$. However, in vertical transport measurements, the current-voltage $(\mathrm{IV})$ characteristics of DBR samples are used to assess the quality of sample contacts.

\section{Results AND Discussion}

To determine the series resistances of vertical DBRs with different diameters, electrical measurements were performed on samples coded VN1743 at a temperature between 13 and $300 \mathrm{~K}$. Fig. 5a-c shows the current-voltage (IV) for 14 periods of $\mathrm{GaAs} / \mathrm{Al}_{0.9} \mathrm{Ga}_{0.1} \mathrm{As}$ on $p$-doped $\mathrm{GaAs}$ substrates (linear DBRs) diameters of $1.4,1.6$, and $1.8 \mathrm{~mm}$, respectively. The results of current-voltage (IV) of DBRs measurements show that the resistance slope for $\mathrm{GaAs} / \mathrm{Al}_{0.9} \mathrm{Ga}_{0.1}$ As based Bragg reflectors are often non-linear and caused by the impurity of the sample. The sample is biased with applied voltages between 1.5 and $2 \mathrm{~V}$. The current for each linear DBRs diameters increases with increasing temperatures from 13 to $300 \mathrm{~K}$. In addition, the current increases with increasing the linear DBRs diameters from 1.4 into $1.8 \mathrm{~mm}$ at $300 \mathrm{~K}$ as indicated in Fig. 5d.

Furthermore, electrical characterization of vertical DBRs of 14 periods of $\mathrm{GaAs} / \mathrm{Al}_{0.3} \mathrm{Ga}_{0.7} \mathrm{As} / \mathrm{Al}_{0.9} \mathrm{Ga}_{0.1} \mathrm{As}$ on the p-doped substrate (coded VN1802) with diameters of 1.4, 1.6 , and $1.8 \mathrm{~mm}$ as a function of temperatures is depicted in Fig. 6a-c. The graded reflectors have a linear $I V$ reaction between 200 and $300 \mathrm{~K}$ because the tunneling distance is affected less by the small bias. The resistance is increased usually with decreasing temperatures due to the thermionic emission method (Nabiev and Chang-Hasnain, 1995). The graded layer drastically reduces the potential barrier of $p$-type DBR (Winston and Hayes, 1998). In addition, the $I V$ measurements of graded DBRs with diameters of 1.4, 1.6, and $1.8 \mathrm{~mm}$ at $300 \mathrm{~K}$ are shown in Fig. 6d. It clearly shows that the current spreading is strongly dependent on the size of mesa sample, which is high in the smallest DBR diameter.

Fig. 7 shows a typical current-voltage (IV) plot for 14 period's $\mathrm{GaAs} / \mathrm{Al}_{0.9} \mathrm{Ga}_{0.1}$ As DBRs (linear) and GaAs/ $\mathrm{Al}_{0.3} \mathrm{Ga}_{0.7} \mathrm{As} / \mathrm{Al}_{0.9} \mathrm{Ga}_{0.1} \mathrm{As}$ DBR (graded) on $p$-doped substrate with three different mesa diameters. It is obvious that current increases by increasing mesa diameters in both linear and graded DBR samples, and leading to reduce the resistance, especially in the graded region.

The fabrication Ohmic contacts were formed with channel main bar length of $1.75 \mathrm{~mm}$ and width of $0.4 \mathrm{~mm}$. A magnetic field of around $0.35 \mathrm{~T}$ is applied perpendicular to the sample. The current flowing through the sample kept relatively low $(<480 \mu \mathrm{A})$ to ensure ohmic conditions. Resistivity as a function of temperature for both linear and graded DBRs (coded VN1743 and VN1802) with diameters of 1.4 and $1.6 \mathrm{~mm}$ is shown in Fig. 8a. Hall Effect measurements of GaAs/AlGaAs heterostructures (coded VN1734 and VN1800) were carried out as a function of temperature between 77 and $300 \mathrm{~K}$. Fig. $8 \mathrm{~b}$ shows the temperature dependence for two types of DBRs, and the inset shows their longitudinal resistivity. The graded sample has lower resistance than the linear sample in the studied temperature range. The inset shows the resistivity as a function of temperature, which exhibit low resistivity compared to the linear DBR sample (Chaqmaqchee, et al., 2012).

\section{Conclusion}

This paper presents an extensive electrical characterization of four types $p$-doped design based linear and graded DBRs using various mesa diameters. DBRs are improved with reduction in the resistance attributed to grading of the layers and smaller mesa diameters. Reducing the resistivity of the quarter wavelength thick is required for the reducing of the heating generation combined with improved thermal conductivity. Thus for optoelectronic devices structure, low series resistance to limit heating effect and sufficient heat dissipation are important to achieve high output power operation. This increases the VCSEL/VCSOA performance, which have great interest in optical fiber communication systems including metro and access networks.

\section{DisClosure}

The authors report no conflicts of interest in this work. 


\section{ACKNOWLEDGMENT}

This research was financially supported by the ministry of higher education and scientific research of IRAQ. FC highly appreciates the support of the University of Essex team during this work. FC also acknowledges Koya University, Department of Physics for allowing this study.

\section{REFERENCES}

Chaqmaqchee, F., Abubekr Salh, S. and Sabri, M.M., 2020. Optical analysis of $1300 \mathrm{~nm}$ GaInNAsSb/GaAs vertical cavity semiconductor optical amplifier, Zanco Journal of Pure and Applied Sciences, 32(2), pp.87-92.

Chaqmaqchee, F.A.I. and Lott, J.A., 2020. Impact of oxide aperture diameter on optical output power, spectral emission, and bandwidth for $980 \mathrm{~nm}$ VCSELs. OSA Continuum, 3(9), pp.2602-2613.

Chaqmaqchee, F.A.I., 2019. Performance characteristics of conventional vertical cavity surface emitting lasers VCSELs at $1300 \mathrm{~nm}$. ZANCO Journal of Pure and Applied Sciences, 31(2), pp.14-18.

Chaqmaqchee, F.A.I., Mazzucato, S., Sun, Y., Balkan, N., Tiras, E., Hugues, M. and Hopkinson, M., 2012. Electrical characterisation of p-doped distributed Bragg reflectors in electrically pumped GaInNAs VCSOAs for 1.3 mu operation. Materials Science and Engineering B, 177(10), pp.739-743.

Croquette, K.D. and Hou, H.Q., 1997. Vertical-cavity surface emitting lasers: Moving from research to manufacturing, Proceedings of the IEEE, 85(11), pp.1730-1739.

Garmire, E., 2003. Theory of quarter-wave-stack dielectric mirrors used in a thin Fabry-Perot filter. Applied Optics, 42, pp.5442-5449.
Macleod, H.A., 2018. Thin-film Optical Filters, CRC Press, Taylor and Francis, Arizona, USA.

Marciniak, M., Gebski, M., Broda, A., Muszalski, J., Czyszanowski, T. and Lott, J.A., 2020. Impact of Top Mirror Power Reflectance on 980-nm VCSEL Performance. Vol. 11300. Proceedings SPIE.

Nabiev, R.F. and Chang-Hasnain, C.J., 1995. Voltage drop in n- and p-type Bragg reflectors for vertical-cavity surface-emitting lasers. IEEE Photonics Technology Letters, 7(7), pp.733-735.

Ogura, M., Hata, T., Kawai, N.J. and Yao, T., 1983. GaAs/Al $\mathrm{Ga}_{1-\mathrm{x}}$ As multilayer reflector for surface emitting laser diode. Japanese Journal of Applied Physics, 22(2A), pp.L112-L114.

Pickrella, G.W., Louderbacka, D.A., Fisha, M.A., Hindia, J.J., Lina, H.C., Simpsona, M.C., Guilfoylea, P.S. and Lear, K.L., 2005. Compositional grading in distributed Bragg reflectors, using discrete alloys, in vertical-cavity surfaceemitting lasers. Journal of Crystal Growth, 280(1-2), pp.54-59.

Pohl, J., Cole, G.D., Zeimer, U., Aspelmeyer, M. and Weyers, M., 2018. Reduction of absorption losses in MOVPE-grown AlGaAs Bragg mirrors. Optics Letters, 43(15), pp.3522-3525.

Wang, G., Li, K., Chen, S. and Yang, H., 2019. Analysis of pulse amplification characteristics in vertical cavity semiconductor optical amplifiers. Journal Integrated Ferroelectrics, 198(1), pp.39-54.

Winston, D.W. and Hayes, R.E., 1998. Optoelectronic device simulation of Bragg reflectors and their influence on surface-emitting laser characteristics, IEEE Journal of Electronics, 34(4), pp.711.

Zhang, C., ElAfandy, R. and Han, J., 2019. Distributed Bragg reflectors for GaN-based vertical-cavity surface-emitting lasers, Applied Sciences, 9(8), pp. 1-20. 